\title{
Tensile Properties and Dye Uptake Assessment of Cotton Fabrics Sized with Corn (Zea mays) Starch and Sorghum (Sorghum bicolor) Starch
}

\author{
Oyetade Joshua Akinropo ${ }^{1, *}$, Adewuyi Oluwafemi ${ }^{2}$ and Akinrinlola Olumide ${ }^{3}$ \\ ${ }^{1}$ Department of Chemistry, Federal University of Technology, Akure, Nigeria \\ e-mail: joshuaoyetade@gmail.com \\ ${ }^{2}$ Department of Chemistry, Federal University of Technology, Akure, Nigeria \\ ${ }^{3}$ Department of Science Laboratory Technology, Osun State College of Technology Esa-Oke, Osun State, \\ Nigeria \\ * Corresponding author
}

\begin{abstract}
Sizing of textile substrate enhances the tenacity of the fibre which gives it an appreciable commercial acceptability. However, the sized textile sample is challenged with dye exhaustion and uptake. This study aimed at investigating the effects of starch molecules on dyeing of textile substrates, the recovery angle and the tenacity of the textile materials. This was carried out by treating pure cotton fabric with starch extracted from corn (Zea mays) and guinea corn (Sorghum bicolor) in the ratio 5\%, 10\%, 15\%, 20\%, 25\% and the percentage starch retention was calculated in $\mathrm{mg} / \mathrm{g}$ while the \%dye uptake was also calculated. The mechanical properties of the sized textile samples were measured using the tensile testing machine and the crease recovery of the textile materials was evaluated. From the results, the maximum wavelength $\left(\lambda_{\max }\right)$ of the dye used was $530 \mathrm{~nm}$. Furthermore, from the sizing of the textile samples, the highest percentage of starch retention was $3.71 \%$ and $2.733 \%$ for corn and sorghum starch respectively. The value of $\%$ dye uptake at $30 \mathrm{~min}$ was $29.25 \%$ and $27.1 \%$ for corn and sorghum sized while the control (i.e. the unsized textile sample) was $85.85 \%$. The crease recovery angle of the $5 \%$ starch concentration was 12 for sorghum sized and 10 for corn sized. This value was recorded as the highest when compared to other percentage concentration of starch. The mechanical properties which measures the tensile strength shows that at $5 \%$ concentration, $14.098 \mathrm{mPa}$ and $20.372 \mathrm{mPa}$ tensile value was observed for sorghum and
\end{abstract}

Received: October 16, 2020; Revised \& Accepted: November 14, 2020

Keywords and phrases: dye uptake, sizing, dye, starch, concentration.

Copyright (C) 2021 Oyetade Joshua Akinropo et al. This is an open access article distributed under the Creative Commons Attribution License, which permits unrestricted use, distribution, and reproduction in any medium, provided the original work is properly cited. 
the corn sized samples respectively when compared to 12.097 value of the control sample. However, the highest tensile strength value was at $10 \%$ starch concentration $(55.798 \mathrm{mPa})$ for sorghum sized samples and $15 \%$ starch concentration for corn sized textile samples.

\subsection{Introduction}

In the polymer, dye and textile industry, cotton has gained prominence among other textile materials and has become the major backbone of textile trade globally. The emphasis placed on this cellulosic material with natural origin is based on its unique features such as high strength, durability, softness, dyeability, biodegradability and lack of static electricity (neutrality towards charge build-up). (Nakamura [1], Wang et al. [2], Blackburn and Burkinshaw [3], Plastina [4]). Cotton consists of 90\%-96\% cellulose and their impurity ranges from $4 \%-10 \%$. These impurities are non-cellulosic components such as waxes, pectins, and proteins. There are generally located within the cuticle layer and the primary wall, which are the outermost layers of the cotton fibers (Raza et al. [5], Rana et al. [6], Zhu et al. [7]). The cellulose predominantly present in the cotton is described as a polymer consisting of $\beta$-D glucopyranose units covalently linked by 1,4glycosidic bonds (Klemm et al. [8], Park et al. [9]). While the functional group present on each glucose unit accounts for its dye fixation as well as chemical modification. Furthermore, various dyes are used for this cellulosic substrate ranging from natural to synthetic dyes. Out of these categories of dyes applied, reactive dyes have gain prominence due to its brilliancy, varieties of hue, and high wash-fastness of reactive dyes, which are anionic in nature (Kannan et al. [10], Chattopadhyay et al. [11], Lewis and Vo [12], Montazer et al. [13], Teng et al. [14]). The chemistry of dyeing cotton with reactive dyes involves the generation of slightly negative charges on the surface of the cellulosic fibres when in contact with water based on the ionization of the hydroxyl groups (Kannan et al. [10], Teng et al. [14]). However, prior to the dyeing process, certain pre-treatment operations are given to textile substrates such as singeing, sizing (application of starch paste to the textile substrate) scouring, bleaching etc. These pretreatment processes imparts certain significant properties such as tensile strength, luster and dyeability to the textile substrate (Adetuyi [15]).

In addition to these, the pre-treatment processes are essential to enhance dye-fibre interaction, forestall consequent bleeding and maximize dye exhaustion from the Dye bath while conserving the tenacity of the textile fibre (Adetuyi et al. [16], Raza et al. [5]). 
The tenacity of fabrics is revealed by its tensile strength which is shown when fabrics are subjected to tensional force (Pan [17], Oyetade [18]). The tensile stress is mathematically expressed as force per unit area of unstrained specimen. While the dyeability of the textile substrate is described by direct dip dyeing, leading to absorption and transportation of the dyes molecules into the fibre matrix of the textile material. Consequent to this is a gradual decrease of dye concentration in the solution (Wang et al. [34]). Attention has been channel toward the use of natural dyes in dyeing base on it low level of toxicological effects. However, these categories of dyes are challenged with poor fastness properties to some vital agencies. Therefore, most natural dyes need chemical species called mordants for binding the dye to fabrics and to improve colour fastness. Mordants help in binding of dyes to fabric by forming a chemical bridge from dye to fiber thus improving the staining ability of a dye with increasing its fastness properties and forestalls subsequent bleeding (Padma [19], Adetuyi et al. [16]).

Many assertions have been made on the need for desizing sized textile materials prior to dyeing operation. These claims were based on the forestalling effect of the starch molecules to the transportation of dye molecules into the fibre matrix of textile materials. Hence, this research focuses on the application of natural dye on sized cellulosic textile substrate with the aim of assessing its level of dye uptake, the crease recovery angle and the tensile strength properties of the material.

\subsection{Materials and Methods}

\subsection{Materials}

The pure cotton fabric was purchased from Oja-oba market in Akure North Local Government of Ondo State, Nigeria. While the sizing materials used were Corn starch (Zea mays) and Guinea corn starch (Sorghum bicolor). Various glass wares such as -100 $\mathrm{ml}$ and $500 \mathrm{ml}$ measuring cylinders, $250 \mathrm{ml}$ beaker, $1000 \mathrm{ml}$ standard flasks, and glass stirrer were obtained from the Department of Chemistry at the Federal University of Technology Akure. Other equipments includes: oven, weighing balance, spatula, hot plate, Bunsen burner and desiccators. While the instruments used were UV-Visible spectrophotometer (1800 Unico-UV) and dyeing machine (ROACHES Model MB) from the central laboratory and Chemistry Department of the Federal University of Technology, Akure Ondo state, Nigeria. 


\subsection{Methods}

\subsubsection{Extraction of starch from corn and sorghum}

The maize grains were handpicked and washed with distilled water to remove the foreign materials. Thereafter, the grains were stepped into distilled water for 72 hours to soften the kernel before grinding (Seetharaman and White [20]). The milled grains (corn meal) were sieved using porcelain cloth of mesh size 5 to remove the chaff (residue) from the filtrate. The filtrate consisting of starch solution was allowed to stand overnight. Then the following day, the water and the corn suspension were decanted off leaving behind the corn starch. The corn starch was dried in an oven at $65^{\circ} \mathrm{C}$ and pulverized to obtain the powdery form of corn starch. The same procedure was repeated for sorghum to extract starch.

\subsubsection{Preparation of starch sizes}

Five (5) distinct weights of corn starch powder $(0.5 \mathrm{~g}, 1.0 \mathrm{~g}, 1.5 \mathrm{~g}, 2.0 \mathrm{~g}, 2.5 \mathrm{~g})$ was weighed out and transferred into five (5) $250 \mathrm{ml}$ beakers respectively. Then $10 \mathrm{ml}$ of distilled water was added and each beaker and swirl, then make up to $100 \mathrm{ml}$ mark at $27^{\circ} \mathrm{C} \pm 0.2^{\circ} \mathrm{C}$. The starch solution in each beaker was stirred with glass rod and the procedure was repeated for starch from sorghum.

\subsubsection{Sizing of the fabric using corn starch and sorghum starch}

Five (5) swabs from the cotton textile sample were cut into dimension of $4 \mathrm{~cm} \times 10$ $\mathrm{cm}$ and the weight were taken as $W_{1}$ (Adetuyi et al. [16], Oyetade [18]). Each of the textile swabs was added into the beaker consisting of starch solution as previously discussed in 2.2.2. These were then heated using a Bunsen burner for 10 minutes. The sized textile samples were then removed and placed in a clean flat board where excess starch paste were removed by pressing out the paste. The fabrics were then placed in an oven set at $105^{\circ} \mathrm{C} / \mathrm{l} \mathrm{hr}$ to dry. The fabrics were cooled inside the desiccators until a constant weight was obtained $\left(W_{2}\right)$. The percentage starch regained using the formular in equation (1)

$$
\text { Percentage Starch Regain }=\frac{W_{2}-W_{1}}{W_{1}} \times 100 .
$$

\subsubsection{Determination of crease recovery angle of the treated fabrics}

Sized textile samples as discussed in 2.2.3 were folded in half across the narrow direction. Then a metal (iron) was placed on the fold for 5 minutes after which they were 
hung on a horizontal wire and left to recover for three minutes. Then with the aid of a protractor the angle formed was measured.

\subsubsection{Determination of the tensile property of the sized fabrics}

The tensile strength of the sized textile samples was determined using the Instron Universal Testing Machine (Model 3396). The load-elongation at break of the above textile material was done at a constant rate of elongation at $500 \mathrm{~N}$ per tension at $25^{\circ} \mathrm{C}$ and Relative humidity of $65 \%$ on Instron universal testing machine Tensile Tester (3396). (Oyetade [18])

\subsubsection{Preparation of dye liquor}

$50 \mathrm{mg}$ of the Pterocarpus dye was weighed into $1000 \mathrm{ml}$ beaker and dissolved with $20 \mathrm{ml}$ of $40 \%$ ethanol, swirl and finally made up to $1000 \mathrm{ml}$ mark. The wave scan of the dye was carried out using UV-Visible spectrophotometer (1800 Unico-UV) from $350 \mathrm{~nm}$ to $750 \mathrm{~nm}$ to determine the maximum wavelength $\left(\lambda_{\max }\right)$. Thereafter, the serial dilution of dye liquor was carried out and its calibration curve plot was obtained at a predetermined wavelength (Adetuyi et al. [21]).

\subsubsection{Dyeing of the sized textile substrate}

$100 \mathrm{ml}$ of already known concentration $\left(C_{i}\right)$ of dye liquor was measured into the dyeing tube. The $10 \%$ sized (corn starch and sorghum starch) and the unsized textile samples cut into previously discussed dimension, were added into each of the dyeing tube in the dyeing machine (ROACHES Model MB) with a liquor to goods ratio of 20:1 (Jabar et al. [22]). The dyeing process was carried out in the dyeing machine for 15 minutes at $60^{\circ} \mathrm{C}$ and $100 \mathrm{rpm}$. The dyeing machine was then allowed to cool and the dyed textile samples were removed. (Mohammed and Loghman [23], Thomas et al. [24]). An aliquot of the used dye liquor was taken to determine its final concentration $\left(C_{f}\right)$. This process was repeated for a dyeing time of 30, 40 and $60 \mathrm{~min}$. the dye uptake was then calculated using the formular in equation (2):

$$
\text { Percentage Dye Uptake }=\frac{C_{i}-C_{f}}{C_{i}} \times 100 .
$$

\subsection{Result and Discussion}

a. Maximum wavelength and calibration curve of the dye stuff

Figure 1 shows the wave scan of the pure Pterocarpus dye having a maximum 
absorption $\left(\lambda_{\max }\right)$ at $530 \mathrm{~nm}$. While Figure 2 shows the calibration curve plot of the natural dye (Pterocarpus dye), having an increasing absorbance as the concentration increases. This behavior obeys the Beer-Lambert law relating increase in the absorbance of colourants to increase in their concentration (Kannan et al. [10]). In addition to this, the value of the $\lambda_{\max }$ agrees with the range of values for spectra and complementary colours (Popoola [25]). Kannanmarikani et al. [26] in his research shows that the natural dye extract from Lawsonia inermis has its maximum absorption which is in tandem with the value of natural dye under study. The use of natural dyes as colourant for substrates has regained another focus based on their ease in biodegradability, versatility and their compatibility with the environment when compared with its synthetic counterparts (Osabohien [27], Otutu et al. [28]). However, they are challenged with poor fastness properties. Hence, the use of mordanting agents to effectively coordinate these natural dyes to substrates (especially textiles), becomes an issue of necessity (Samanta and Agarwal [29], Jothi [30]).

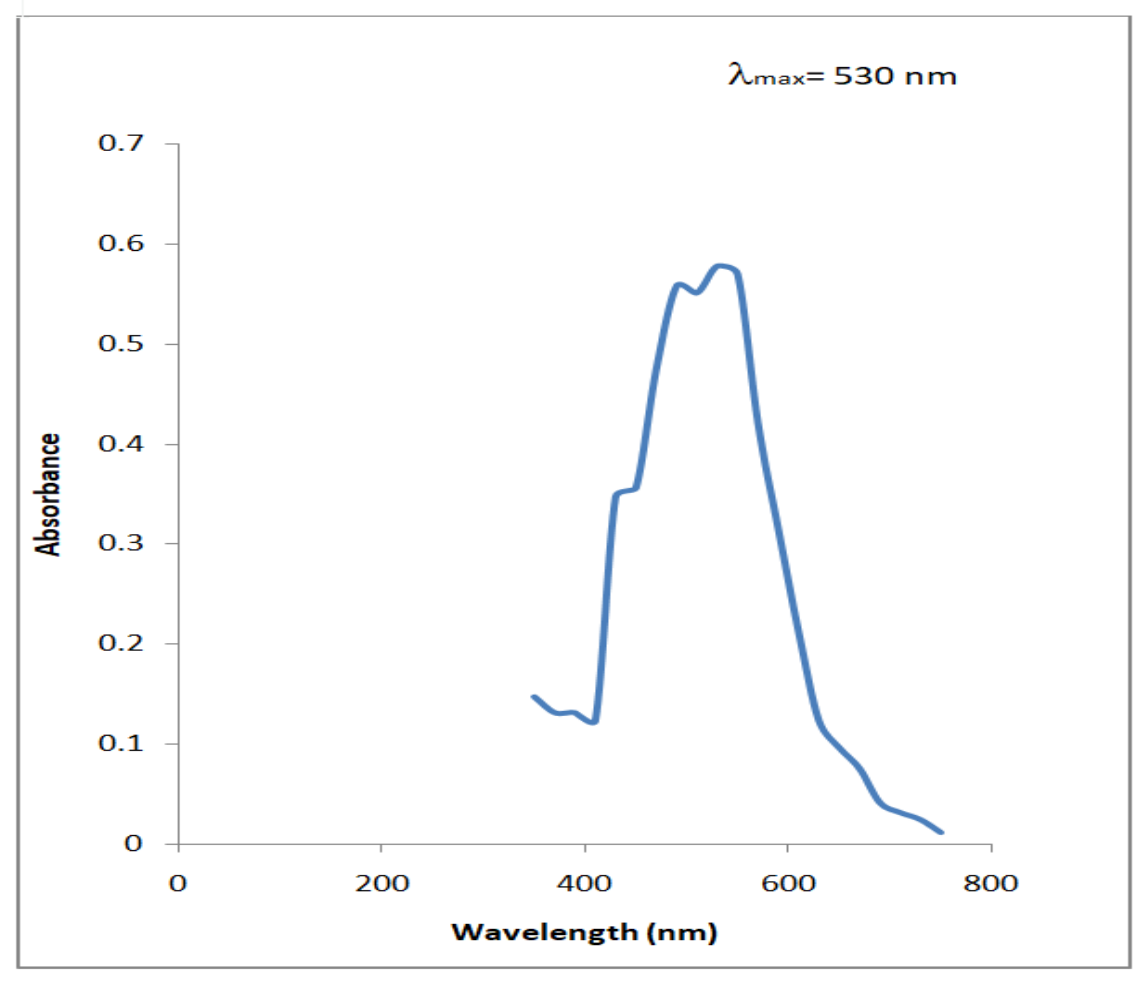

Figure 1. Wave scan of Pterocarpus dye. 


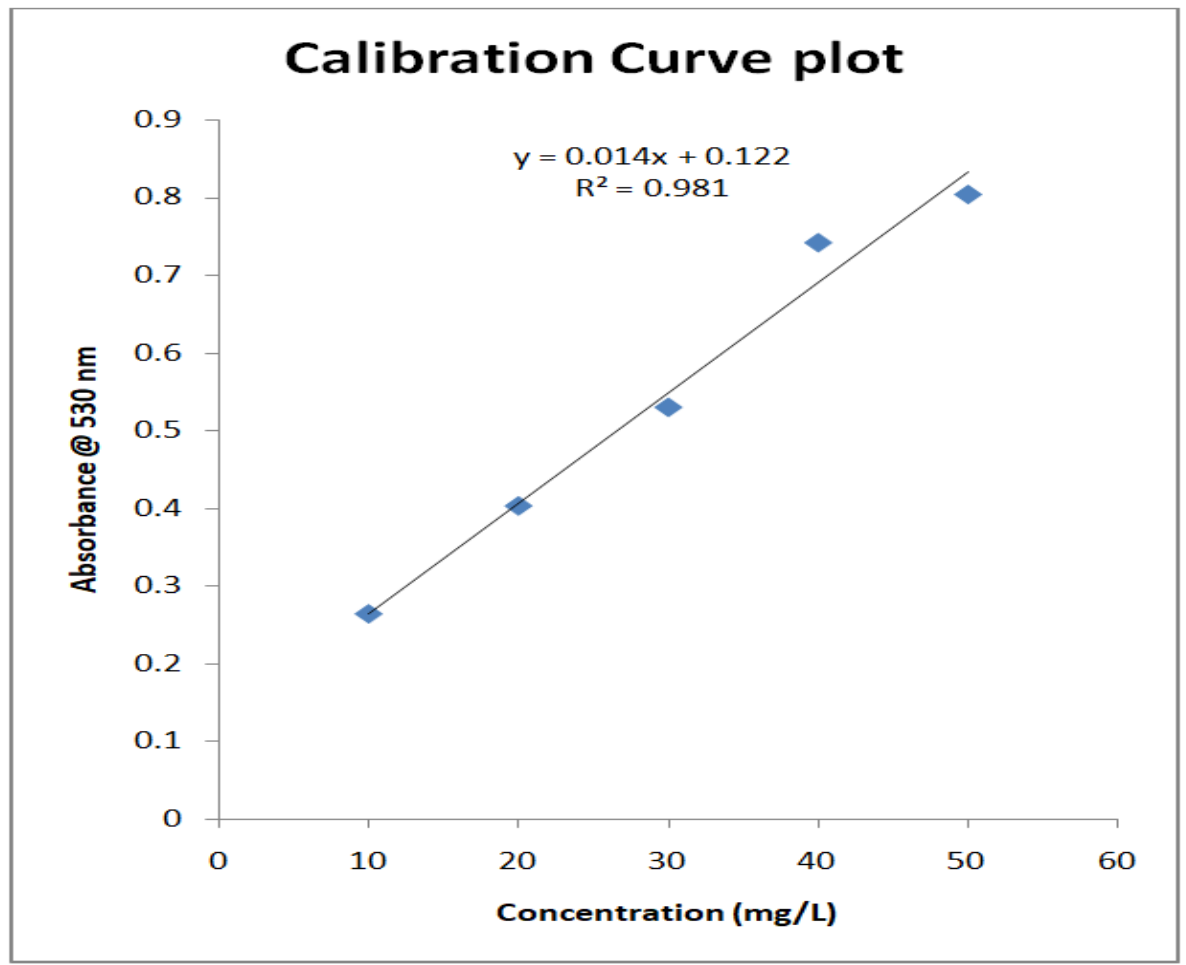

Figure 2. Calibration curve plot of Pterocarpus dye at $530 \mathrm{~nm}$.

\section{b. Percentage starch retained}

Figure 3 shows the percentage of starch retained by the textile samples at varying concentration of starch from maize and guinea corn. From the results, the cotton textile sized with maize has the highest starch retained $(3.71 \%)$ at $10 \%$ starch concentration. While for the cotton textile sized with guinea corn starch has its highest percentage of starch retained to be $2.733 \%$ at $10 \%$ starch concentration. The percentage of starch retained by textile samples is similar to the result of obtained by Selamu et al. [31]. However, from Figure 3 there was a sharp decrease in the percentage of starch retained with respect to increasing starch concentration. Sizing plays an important role especially by improving the physicochemical properties of the textile material and to generally enhance its tenacity to external force (Schwarz et al. [32]). Kovacevic et. al. [33]) in his research submits that deep sizing of textile or its yarn prior to woven operation plays an important role in forming outer protection of the threads. 


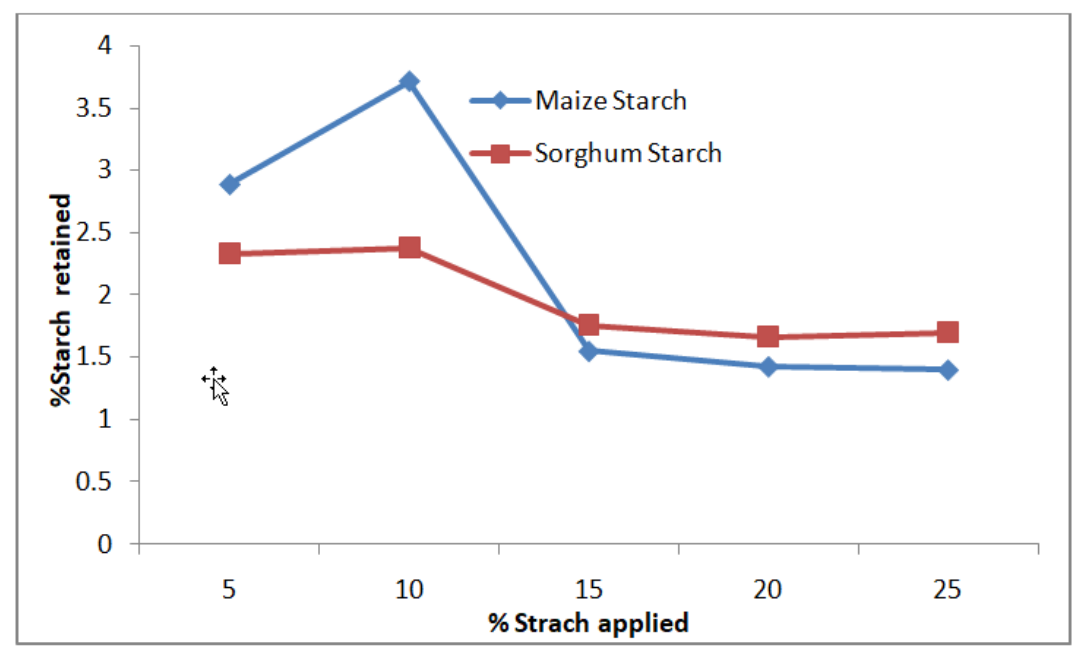

Figure 3. Percentage starch retained on the sized textile samples.

\section{c. Percentage dye uptake of sized textile samples}

Figure 4 reveals the percentage dye uptake of textile samples sized with their respective starch in comparison with unsized textile samples (control). From the results, the optimum dyeing time took place in 30 minutes for maize and sorghum sized textile samples with a percentage dye uptake of (29.25\% and $27.1 \%)$. This value compared with the control $(85.85 \%)$ shows that the starch content locked up in fibre matrix of the textile samples forestalls the absorption and transportation of dye molecules from the dye bath into the fibre of the textile substrate. This behavior is justified by claims on the vital importance of pretreatment operations of textile samples (especially desizing), prior to dyeing to enhance efficient dye uptake by the textile substrate and to reduce consequent bleeding (Adetuyi [15], Adetuyi et al. [16], Raza et al. [5]). In addition to this, Loum et al. [34] reveals the importance of desizng prior to dyeing to enhance dye-fibre interaction. While Jabar et al. [22] and Adetuyi [15] added that, the desizing techniques can carried out by enzymatic solubilization or chemical treatment of sized substrate before dyeing. Furthermore, it is imperative to add that from the discussion at (b), the amorphous orientation of the corn starch compared to the more ordered orientation (crystalline) of the sorghum starch on the surface and inside the fibre matrix of the textile samples may account for its higher percentage dye uptake. This is because less ordered arrangement of starch molecules and fibre matrix of the textile substrate facilitate higher percentage dye uptake when colourants are applied [29]. 


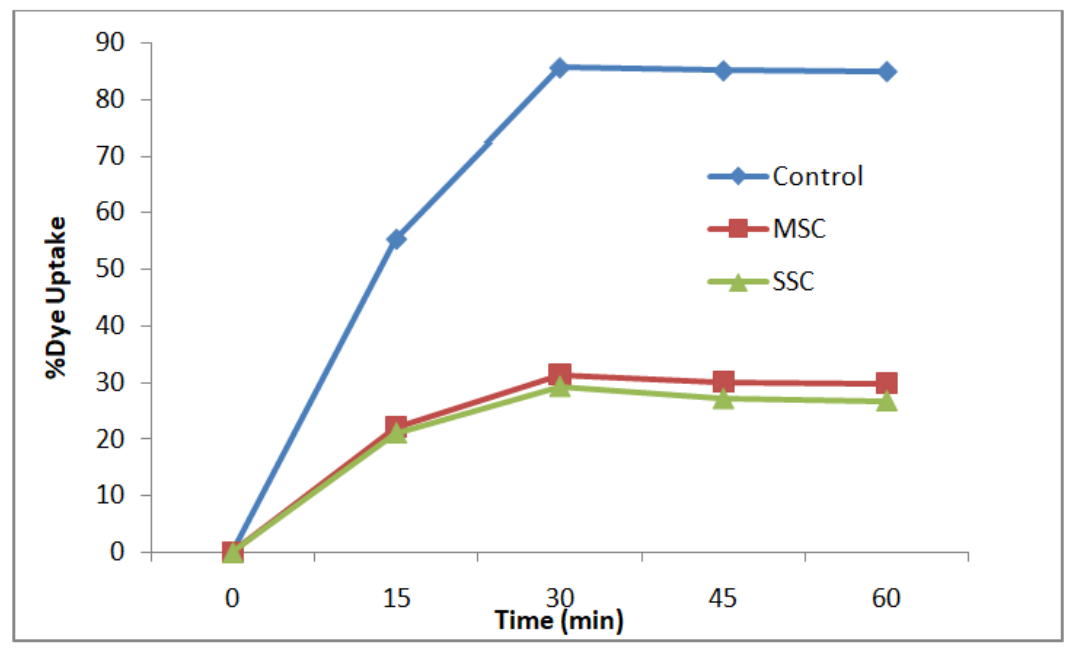

Figure 4. Percentage dye uptake of the sized textile samples.

Key: MSC: Maize sized Cotton; GSC: Guinea Corn sized cotton

\section{d. Crease recovery angle of the sized textile samples}

Table 1 shows the crease recovery angle of the maize and sorghum sized textile samples. From the Table, the textile samples sized with $5 \%$ of the starch from maize and sorghum has the highest crease recovery angle of 12 and 10 respectively. These recorded values are lower to values recorded from the study carried out by Karthik et al. [35] and Obiana et al. [36]. However, as the concentration of the starch paste applied increases, the crease recovery angle decreases. This implies that the 5\% sized textile samples need less ironing than the textile samples with higher concentration of the starch paste (Obiana et al. [36]).

Table 1. Crease recovery angle (degree) of sized textile samples.

\begin{tabular}{ccc}
\hline $\begin{array}{c}\text { Weight of starch } \\
\text { applied }\end{array}$ & $\begin{array}{c}\text { Crease recovery } \\
\text { angle } \\
\text { for Sorghum }\end{array}$ & $\begin{array}{c}\text { Crease recovery angle for } \\
\text { Corn }\end{array}$ \\
\hline $5 \%$ & 12 & 10 \\
$10 \%$ & 8 & 9 \\
$15 \%$ & 5 & 7 \\
$20 \%$ & 3 & 6 \\
$25 \%$ & 2 & 4 \\
\hline
\end{tabular}




\section{e. Tensile Properties of Sized Textile Samples}

Tables 2 and 3 reveal the values of the tensile strength properties of textile samples sized with starch from sorghum and maize respectively. From the tables, the tensile strength value of the textile sample sized with sorghum starch at $5 \%$ starch concentration was $14.098 \mathrm{mPa}$ while $20.372 \mathrm{mPa}$ was the value of textile sample sized with maize starch. Both values are higher when compared with to the control textile (i.e. textile sample not sized), having a tensile strength value of $12.097 \mathrm{mPa}$ but higher elongation at break $(20.05 \mathrm{~mm} / \mathrm{mm})$. In addition to this, there was a significant increase of $55.796 \mathrm{mPa}$ at $10 \%$ starch concentration for sorghum sized textile. This value happens to be the highest. However, the highest tensile strength value observed for maize sized textile at $15 \%$ starch concentration was $46.36 \mathrm{mPa}$, with higher elongation at break. These exhibited properties agree with the percentage of starch retained by the sized textile samples in Figure 3. Furthermore, this progression was in agreement with the research carried out by Temesgen et al. [31]. In addition to these, the results suggest that the variation in the value of tensile strength may be due to the varying concentration of starch paste applied and at concentration above $10 \%$ for sorghum and $15 \%$ for corn, lower the starch retention is observed (from discussion in Figure 3) leading to the reduction in their tensile strength values.

The tensile strength properties of woven fabrics are a complex phenomenon and can be affected by different constructional parameters and various pre-treatment processes given to the fabrics of which sizing is predominant (Gürkan Ünal and Taşkın [27]). Maatoug et al. [38] affirms that the sizing agent (predominantly starch paste) are used to improve the stiffness, strength and smoothness of yarns which confirm the reason for the reduction of the elongation of the sized textile materials as the percentage of starch paste applied increases.

Table 2. Tensile properties of sorghum starch sized textile samples.

\begin{tabular}{lllllll}
\hline $\begin{array}{l}\text { Starch } \\
\text { sizes }\end{array}$ & $\begin{array}{l}\text { Modulus } \\
(\mathbf{m P a})\end{array}$ & $\begin{array}{l}\text { Tensile stress } \\
\text { at yield }(\mathbf{m P a})\end{array}$ & $\begin{array}{l}\text { Tensile stress } \\
\text { at break } \\
(\mathbf{m P a})\end{array}$ & $\begin{array}{l}\text { Tensile strain } \\
\text { at yield } \\
(\mathbf{m m} / \mathbf{m m})\end{array}$ & $\begin{array}{l}\text { Tensile strain } \\
\text { at break } \\
(\mathbf{m m} / \mathbf{m m})\end{array}$ & $\begin{array}{l}\text { Tensile } \\
\text { elongation at } \\
\text { break } \\
(\mathbf{m m} / \mathbf{m m})\end{array}$ \\
\hline Control & 113.40518 & 12.09752 & -0.35449 & 0.13923 & 0.15423 & 20.05000 \\
$\mathbf{5 \%}$ & 695.17579 & 14.09842 & 12.61131 & 0.05071 & 0.06260 & 8.76406 \\
$\mathbf{1 0 \%}$ & 447.82991 & 55.79563 & -4.29769 & 0.14643 & 0.15107 & 21.1500 \\
$\mathbf{1 5 \%}$ & 363.10163 & 50.43600 & 1.33574 & 0.17929 & 0.18572 & 26.00015 \\
$\mathbf{2 0 \%}$ & 372.52833 & 41.51832 & 28.93783 & 0.15072 & 0.15536 & 21.75031 \\
$\mathbf{2 5 \%}$ & 320.99684 & 44.55279 & 2.77705 & 0.17286 & 0.17750 & 24.85015 \\
\hline
\end{tabular}


Table 3. Tensile properties of maize starch sized textile samples.

\begin{tabular}{lllllll}
\hline $\begin{array}{l}\text { Starch } \\
\text { sizes }\end{array}$ & $\begin{array}{l}\text { Modulus } \\
(\mathbf{m P a})\end{array}$ & $\begin{array}{l}\text { Tensile stress } \\
\text { at yield }(\mathbf{m P a})\end{array}$ & $\begin{array}{l}\text { Tensile stress } \\
\text { at break }(\mathbf{m P a})\end{array}$ & $\begin{array}{l}\text { Tensile strain } \\
\text { at yield } \\
(\mathbf{m m} / \mathbf{m m})\end{array}$ & $\begin{array}{l}\text { Tensile strain } \\
\text { at break } \\
(\mathbf{m m} / \mathbf{m m})\end{array}$ & $\begin{array}{l}\text { Tensile } \\
\text { elongation at } \\
\text { break } \\
(\mathbf{m m} / \mathbf{m m})\end{array}$ \\
\hline $\mathbf{5 \%}$ & 170.89748 & 20.32577 & 1.00328 & 0.16822 & 0.17142 & 20.50031 \\
$\mathbf{1 0 \%}$ & 299.61182 & 32.91183 & 27.50591 & 0.15464 & 0.16138 & 22.59297 \\
$\mathbf{1 5 \%}$ & 362.42193 & 46.36028 & 4.46266 & 0.14750 & 0.17500 & 24.49984 \\
$\mathbf{2 0 \%}$ & 358.86626 & 36.30253 & 13.65674 & 0.11321 & 0.12554 & 17.57609 \\
$\mathbf{2 5 \%}$ & 194.13252 & 24.49342 & 1.2012 & 0.17786 & 0.18174 & 25.44406 \\
\hline
\end{tabular}

\subsection{Conclusion}

From the investigation carried out on the cotton textile samples sized with sorghum and maize starch respectively, the textile samples sized with maize starch has higher starch retention when compared with its counterpart at 10\% starch concentration. Furthermore, the dye uptake of each sized textile samples was very low when compared with the control textile. This justifies the forestalling potential of starch present in the fibre matrix of the textile samples to dye absorption and transportation. However, the tenacity of the textile was significantly enhanced when sized with the starch paste from sorghum and maize. This is displayed in their high elongation at break results, low stiffness characteristics, good fabric thickness, which indicates a good diameter increment on yarn which makes up the fabrics.

\section{References}

[1] A. Nakamura, Fiber Science and Technology, Science Publishers, USA, 2000.

[2] Y. Wang, D.S. Chen, X. Lin and W.Z. Wang, The dyeing properties of natural cotton fabric, Materials Research Innovations 19 (2015), S6-82-S6-84. https://doi.org/10.1179/1432891715Z.0000000001453

[3] R.S. Blackburn and S.M. Burkinshaw, Treatment of cellulose with cationic, nucleophilic polymers to enable reactive dyeing at neutral $\mathrm{pH}$ without electrolyte addition, J. Appl. Polym. Sci. 89 (2003), 1026-1031. https://doi.org/10.1002/app.12226

[4] A. Plastina, Cotton's share of world textile fiber use continues to decline, 2009. Accessed 27 Apr 2012: http://www.icac.org/meetings/plenary/68_cape_town/documents/bo3/bo3_e_icac.pdf

[5] Z.A. Raza, A. Rehman, M.T. Hussain, R. Masood, A. ul Haq, M.T. Saddique, A. Javid and N. Ahmad, Production of rhamnolipid surfactant and its application in bioscouring of cotton fabric, Carbohydr. Res. 391 (2014), 97-105.

https://doi.org/10.1016/j.carres.2014.03.009 
[6] M. Rana, J.-T. Chen, S. Yang and P.-C. Ma, Biomimetic superoleophobicity of cotton fabrics for efficient oil-water separation, Adv. Mater. Interfaces 3 (2016), 1600128. https://doi.org/10.1002/admi.201600128

[7] B. Zhu, J. Liu and W. Gao, Effects of snailase treatment on wettability of raw cotton yarns in pre-wetting process of foam sizing, Appl. Biochem. Biotechnol. 182 (2017), 1065-1075. https://doi.org/10.1007/s12010-016-2382-3

[8] D. Klemm, B. Heublein, H.P. Fink and A. Bohn, Cellulose: fascinating biopolymer and sustainable raw material, Angew. Chemie Int. Ed. 44 (2005), 3358-3393. https://doi.org/10.1002/anie.200460587

[9] S. Park, J.O. Baker, M.E. Himmel, P.A. Parilla and D.K. Johnson, Cellulose crystallinity index: measurement techniques and their impact on interpreting cellulase performance, Biotechnol. Biofuels 3 (2010), Article number: 10.

https://doi.org/10.1186/1754-6834-3-10

[10] M.S.S. Kannan, M. Gobalakrishnan, S. Kumaravel, R. Nithyanadan, K.J. Rajashankar and T. V. Adicherala, Influence of cationization of cotton on reactive dyeing, Text. Appar. Technol. Manag. 5 (2006), 23-30.

[11] D.P. Chattopadhyay, R.B. Chavan and J.K. Sharma, Salt-free reactive dyeing of cotton, Int. J. Cloth. Sci. Technol. 19 (2007), 99-108. https://doi.org/10.1108/09556220710725702

[12] D.M. Lewis and L.T.T. Vo, Dyeing cotton with reactive dyes under neutral conditions, Color Technol. 123 (2007), 306-311. https://doi.org/10.1111/j.1478-4408.2007.00099.x

[13] M. Montazer, R.M.A. Malek and A. Rahimi, Salt free reactive dyeing of cationized cotton, Fibers Polym. 8 (2007), 608-612. https://doi.org/10.1007/BF02875997

[14] X. Teng, W. Ma and S. Zhang, Application of tertiary amine cationic polyacrylamide with high cationic degree in salt-free dyeing of reactive dyes, Chin. J. Chem. Eng. 18 (2010), 1023-1028. https://doi.org/10.1016/S1004-9541(09)60163-4

[15] Abayomi Adetuyi, Dye and textile chemistry technology, Private Discussion, Lecture Note I, Pg 13, November 2012.

[16] Adetuyi Abayomi, Jabar Jamiu, Oyetade Joshua, Ugwu Judith, Abe Taiwo and Fagbenro Moyo, Preparation and performance evaluation of an active anti-bleeding solution for laundering multicoloured textile apparels, Chemistry Journal 5(1) (2020), 1-14.

[17] N. Pan, Relationship between grab and strip tensile strengths for fabrics with roughly linear mechanical behavior, Textile Res. J. 73(2) (2003), 165-171.

https://doi.org/10.1177/004051750307300213 
[18] Oyetade Joshua Akinropo, Preparation of an active anti-bleeding solution for the bleeding Textile apparel, M. Tech Thesis, Department of Chemistry, Federal University of Technology Akure, Nigeria (unpublished), 2018, 134 pp.

[19] S. V. Padma, Chemistry of Natural Dyes, General Article, Facility for Ecological and Analytical Testing (FEAT) at the Indian Institute of Technology, Kanpur 208016, Indian Reson. 2000, pp.73-80.

[20] Y. Ji, K. Seetharaman and P.J. White, Optimizing a small-scale corn-starch extract method for use in the laboratory, Cereal Chem. 81(1) (2004), 55-58.

https://doi.org/10.1094/CCHEM.2004.81.1.55

[21] A.O. Adetuyi, J.M. Jabar, A.O. Obaseki and A.V. Popoola, Adsorption of C.I. Vat Blue 1 (Indigo) from stimulated dyeing effluent on some prepared activated bio-solids, Asian Dyers 6 (2009), 42-49.

[22] J.M. Jabar, A.A. Mojibola and K.A. Alabi, Effect of rate of dyeing on the fastness properties of indigo dyed cotton fabrics, Proceedings of the 4th Annual Conference of The Association of Textile Technologists of Nigeria held at Yaba College of Technology, Yaba, Lagos, 10-13th October 2011.

[23] Mohammed Mirjalili and Loghman Karimi, Extraction and characterization of natural dye from green Walnut Shell and its use in dyeing polyamide: focus on antibacterial properties, Journal of Chemistry 2013 (2013), Article ID 375352.

https://doi.org/10.1155/2013/375352

[24] B. Thomas, M. Amalid and M. Rita, Natural dyes for textile dyeing: A comparison of methods to assess the quality of Canadian golden rod plant material, Dyes and Pigments 75 (2007), 287-293. https://doi.org/10.1016/j.dyepig.2006.06.004

[25] A.V. Popoola, The Chemistry of Colours in Dyes and Pigments, Witd Publishing Ltd., Allen (TX, US) and Lagos (Nigeria), 2015.

[26] Kannanmarikani, Uma Sangareswari Kannan and Rajarathinam Kanniappan, Assessment of dyeing properties and quality parameters of natural dye extracted from Lawsonia inermis, European Journal of Experimental Biology 5(7) (2015), 62-70.

[27] E. Osabohien, The extraction and utilization of natural dyestuffs from dongoyaro plant, Journal of the Chemistry Advancement Society 7 (2009), 184-190.

[28] J.O. Otutu, E. Osabohien and E.M. Efurhievwe, Extraction of natural dyes for textiles dyeing from the by-products of the timber industry, Biosci. Biotechnol. Res. Asia 7(1) (2010), 87-92.

[29] A.K. Samanta and P. Agarwal, Application of natural dyes on textiles, Indian Journal of Fibre \& Textile Research 34 (2009), 384-399. 
[30] D. Jothi, Extraction of natural dyes from African marigold flowers (Tagetes erecta L.) for textile coloration, Autex Research Journal 8 (2008), 49-53.

[31] Selamu Temesgen, Bharani Murugesan and Rotich K. Gideon, Performance evaluation of cotton yarn sized with natural starches produced from native corn, cassava and potato starches, Journal of Textile Science \& Engineering 9(1) (2019), 389. https://doi.org/10.4172/2165-8064.1000389

[32] I.G. Schwarz, S. Kovacevic and K. Dimitrovski, Comparative analysis of the standard and pre-wet sizing process, FIBRES \& TEXTILES in Eastern Europe 19(4) (2011), 135141.

[33] S. Kovacevic and Z. Penava, Impact of sizing on physico-mechanical properties of yarn, FIBRES \& TEXTILES in Eastern Europe 12(4) (2004), 32-36.

[34] Loum Janani, Lukyambuzi Hillary and Kodi Phillips, Mordanting methods for dyeing cotton fabrics with dye from Albizia coriaria plant species, International Journal of Scientific and Research Publications 4(10) (2014).

[35] T. Karthik, R. Rathinamoorthy and R. Ramachandra, Enhancement of wrinkle recovery angle of cotton fabric using citric acid cross-linking agent with nano- $\mathrm{TiO}_{2}$ as a cocatalyst, Journal of Industrial Textile 42(2) (2011), 99-117. https://doi.org/10.1177/1528083711427481

[36] V.U. Obiana, M.F. Aruwan and S. Abdullahi, Comparative effect of laundering using soap and detergent on the fading properties of Nigerian and foreign made wax print fabrics, Nigerian Journal of Textiles 3 (2017), 1-8.

[37] P. Gürkan Ünal and C. Taşkın, The effect of weave and densities on tensile strength of 100\% polyester fabrics, Textiles and Apparel 17(2) (2007), 115-118.

[38] S. Maatoug, N. Ladhari and F. Sakil, Evaluation of the weavability of sized cotton warps, Autex Research Journal 8(4) (2007), 239-244. 